\title{
Satisfying the Energy Demand of a Rural Area by Considering the Investment on Renewable Energy Alternatives and Depreciation Costs
}

\author{
Masoud Rabbani, Yaser Rahimi, Seyed Mahmood Kazemi, and Mehran Samavati \\ Department of Industrial Engineering, College of Engineering, University of Tehran, P.O. Box 11155-4563, Tehran, Iran \\ Correspondence should be addressed to Masoud Rabbani; mrabani@ut.ac.ir
}

Received 13 December 2013; Revised 28 April 2014; Accepted 19 May 2014; Published 29 June 2014

Academic Editor: Pallav Purohit

Copyright (C) 2014 Masoud Rabbani et al. This is an open access article distributed under the Creative Commons Attribution License, which permits unrestricted use, distribution, and reproduction in any medium, provided the original work is properly cited.

\begin{abstract}
In this paper, a fuzzy multiobjective model which chooses the best mix of renewable energy options and determines the optimal amount of energy to be transferred from each resource to each end use is proposed. The depreciation of equipment along with time value of money has been taken into account in the first objective function while the second and the third objective functions minimize the greenhouse gas emissions and water consumption, respectively. Also, this study is one of the pioneer works that has considered demand-side management (DSM) as a competitive option against supply-side alternatives for making apt energy planning decisions. Moreover, the intrinsic uncertainty of demand parameter is considered and modeled by fuzzy numbers. To convert the proposed fuzzy multiobjective formulation to a crisp single-objective formulation the well-known fuzzy goal programming approach together with Jimenez defuzzifying technique is employed. The model is validated through setting up a diversity of datasets whose data were mostly derived from the literature. The obtained results show that DSM programs have greatly contributed to cost reductions in the network. Also, it is concluded that the model is capable of solving even large-scaled instances of problems in negligible central processing unit (CPU) times using Lingo 8.0 software.
\end{abstract}

\section{Introduction}

Although using renewable energy resources is one of the primary solutions for overcoming poverty and achieving sustainable development, for centuries, the focus has been solely on traditional sources of energy. Nonetheless, there are some difficulties with employing the newly introduced sources of energy such as cultural barriers, lack of proper mentality, and budget estimation difficulties to inhibit the growth of renewable energy in the countryside. Thus, it is imperative for mankind to seek a way for solving such challenges (Kazemi and Rabbani) [1].

Shifting from nonrenewable energies to renewable energy technologies (RETs) should be of the top preferences in the direction toward acquiring a satisfactory energy system. Increasing the penetration of RETs not only contributes to meeting the ongoing increasing energy demand but also decreases the adverse environmental effects of burning fossil fuels. Recent studies offer that renewable energy sources are capable of meeting a remarkable portion of the energy demand even at the current level of technological development. However, as discussed before, this may not occur unless the issues that obstruct the penetration of RETs are properly addressed [2-4].

One of the most leading factors that highly affect the apt selection of mixed RETs is the appropriate budget management. To do so, the time value of money should be acutely taken into account in making decisions for energy planning. Moreover, uncertain demand of energy, equipment's depreciation strategies, and environmental impacts of energy technologies make the planning process much more complicated. Therefore, to address such important concerns, in this paper, a fuzzy multiobjective formulation that simultaneously optimizes total costs of the energy system, greenhouse gas emissions, and water consumption of RETs during their life cycles is presented. To deal with the uncertain nature of 
the problem, Jimenez method together with fuzzy goal programming approach has been employed [5].

The remainder of the paper is organized as follows. In Section 2 a review of the related literature is presented. The model and assumptions are presented in Section 3. Afterward, Sections 4 and 5 describe the defuzzification procedure followed by the employed fuzzy goal programming approach, respectively. Computational results are reported in Section 6, followed by concluding remarks in Section 7 .

\section{Literature Review}

Over the past few years, providing energy for rural development has been a challenging issue and received significant attention in most developing countries.

Hain et al. [6] summarized the energy policies according to the UK Government consideration to reach its recyclable targets. The policies are designed according to Renewable Obligation Certificates for large-scale energy-related projects. Bergmann et al. [7] estimate costs and benefits for the case of renewable technologies in Scotland, a country with ambitious targets to advance ecofriendly energy, as well as external effects on landscape, wildlife, and air quality. Thiam [8] in their study attempts to investigate price support of market penetration of renewable energy in developing nations through a decentralized supply process. Also, Bergmann et al. [9] curb the investigation to a specific technology that includes hydro-, on-shore, and off-shore wind power, biomass production, and combustion as the main renewable energy. On the other hand, Mainali and Silveira [10] discuss renewable energy based on rural electrification supply models, the related economical issues, and market distribution in the rural areas of Nepal. Markets for the mentioned energy technologies are currently emerging in Nepal as a consequence of increasing rural electrification in the country.

A review of the rural energy sector in Ethiopia has been proposed by Wolde-Ghiorgis [11]. They analyze the proportion of investment in energy sector in Ethiopia and demonstrate that the current national energy policy for Ethiopia needs complete revision.

Considering hour-by-hour energy availability and demand, Nakata et al. [2] exploit mathematical modelling to minimize the cost of system operation to provide electricity and thermal in rural areas of Japan.

Zhu et al. [12] present the status of China's rural RETs and their internal demand. Hiremath et al. [13] conducted a review of the potential for decentralized power generation and effort made in India to accomplish such systems. This research shows the feasibility of decentralized energy selection for the residential and small scale usage in a rural or a cluster of villages. Liu et al. [14] examine rural community acceptance of renewable energy deployment, showing that rural people embrace renewable energy expansion and its positive effects on environment.

Liming [15] describes the current condition of rural renewable energy (RRE) in China and India and studies the environment, channels, tools, and innovative structure of financing rural renewable energy. Winkler et al. [16] reveal one of the most important effects shaping the results of energy models is the presumptions they make about technology learning the limit to which technologies get inexpensive over time.

Purohit et al. [17] point to a main shortage of energy in rural regions of the developing countries. Zhang et al. [18] believe that more investment in rural infrastructures not only decreases the tax burden on the countryside but also results in more firm management of rural energy consumption especially of the rural enterprises.

In a recent study, Kazemi and Rabbani [1] proposed an integrated decentralized energy planning (DEP) model wherein DSM policies were aptly regarded as a competitive solution against the supply-side alternatives for electrifying a rural area. Based on their obtained results, DSM policies were contributing to electrifying the supposed area at their maximum capacity. Additionally, they considered environmental measures in their study to make the plan more sustainable. However, a significant shortcoming of their work is that they have overlooked considering depreciation costs in their study.

To the best of our knowledge, although it is evidently proven that every renewable energy source will lead to depreciation, there is a narrow body of research considering depreciation in rural renewable energy. So, this paper will consider the depreciation for the first time in the relevant literature.

\section{Proposed Model}

3.1. Problem Description. As mentioned in Section 1, although preparing and using the renewable energy resources, especially in rural areas, have many advantages, there are so many different costs that the lack of an apt planning could result in wasting a large budget. In this paper, four renewable energy options and four end-uses have been considered. To obtain the optimal amount of energy transferred from each option to each end-use, an integer multiobjective programming model has been proposed.

Indeed, one of the most important expenses related to preparing the energy resources is the initial fixed cost of providing the field and installing the equipment. Although this kind of cost includes a large portion of budget, it has not been considered a lot in the literature. In our model, this initial cost is minimized. Also, since the installed equipment would be depreciated after some years, the depreciation issues must be considered in this kind of projects. Therefore, in this paper, we have tried to choose renewable energy options with less depreciation. This point also has not yet been proposed in the literature.

Another contribution is that the demand parameter has been considered to be fuzzy. Indeed, despite the existence of many estimation methods, we are still not able to make sure of the exact amount of demand and that is why we assumed this uncertain parameter to be fuzzy. In addition, as this kind of projects would be applied for a long time, cash time value must be considered. Thus, our programming model minimizes the costs regarding the time value of money. Considering time value of money has resulted in constructing a dynamic model that consists of multiperiods. Moreover the following assumptions are considered. 
(i) Each of renewable energy resources includes several types.

(ii) The greenhouse gas emissions produced in the entire life cycle of renewable energy technologies are taken into account.

(iii) The area under study is a hypothesis area with the data of global average taken from the literature.

3.2. Mathematical Model. In this section, the integer multiobjective fuzzy programming model is described.

Notations. We have the following.

Sets

I: Set of renewable energy technologies

$J$ : Set of end-uses

$S$ : The number of sources in each renewable energy

$T$ : Set of periods.

\section{Parameters}

$\mathrm{Lu}_{i}$ : The area needed for resource $i\left(\mathrm{~m}^{2}\right)$

$r$ : The value of investment rate of return

$e_{i}$ : The fixed cost of occupying the field $\left(\$ / \mathrm{m}^{2}\right)$

$C_{i j}$ : Electricity generation cost of resource $i$ for $j$ th end-use $(\$ / \mathrm{kWh})$

$\mathrm{SA}_{i s}$ : Capacity of resource $i$, type $s$, which is producible throughout the planning horizon (kWh)

$\widetilde{D_{j t}}:$ Demand of end-use $j$ in period $t(\mathrm{kWh})$

$\mathrm{CC}_{i}$ : The initial cost of setting up resource $i$

$\mathrm{CDSM}_{j}$ : Electricity saving cost using the implemented demand side management program in the $j$ th end-use $(\$ / \mathrm{kWh})$

$\mathrm{GHG}_{i}$ : Greenhouse gas emissions of the $i$ th resource option $\left((\mathrm{g} / \mathrm{kWh}) \mathrm{CO}_{2}\right)$

$\eta_{i j}$ : Conversion efficiency for the $i$ th resource option for $j$ th end-use

$\alpha_{1}$ : Feasibility degree of satisfying the demand

$P_{j}$ : The maximum possible saving using the DSM program in the $j$ th end-use $(\mathrm{kWh})$

$\mathrm{WC}_{i}$ : Water consumption of $I$ th resource option $(\mathrm{kg} / \mathrm{kWh})$

$N_{i s}$ : Depreciable life of renewable energy $i$, type $s$

$B_{i s}$ : Original installed cost of renewable energy $i$, type $s$ (this cost is related to the depreciation calculation)

$K$ : The number of options must be chosen.

\section{Decision variables}

Dep $_{i t s}$ : Amount of depreciation of renewable energy equipment (resource) $i$, type $s$, in period $t$

$y_{i} \begin{cases}1 & \text { if renewable energy } i \text { is installed } \\ 0 & \text { othewise }\end{cases}$
$X_{i j t s}$ : Optimal amount of $i$ th resource option (type $s$ ) for $j$ th end-use in period $t(\mathrm{kWh})$

SDSM $_{j t}$ : Optimal saving in $j$ th end-use, using the implemented DSM program in period $t$.

Model. We have the following.

Minimize total cost

$$
\begin{aligned}
& \sum_{i \in I}\left(\mathrm{Lu}_{i} \times e_{i}+\mathrm{CC}_{i}\right) y_{i}+\sum_{i \in I} \sum_{j \in J} \sum_{t \in T} \sum_{s \in S} X_{i j t s} C_{i j} \times\left(\frac{p}{f}, r, t\right) \\
& +\sum_{t \in T} \sum_{j \in J} \operatorname{SDSM}_{j t} \mathrm{CDSM}_{j} \times\left(\frac{p}{f}, r, t\right) \\
& +\sum_{i \in I} \sum_{s \in S} \sum_{t \in T} \operatorname{Dep}_{i t s} y_{i} \times\left(\frac{p}{f}, r, t\right) .
\end{aligned}
$$

Minimize total greenhouse gas emissions

$$
\sum_{i \in I} \sum_{j \in J} \sum_{t \in T} \sum_{s \in S} X_{i j t s} \mathrm{GHG}_{i}
$$

Minimize total water consumption

$$
\sum_{i \in I} \sum_{j \in J} \sum_{t \in T} \sum_{s \in S} X_{i j t s} \mathrm{WC}_{i}
$$

subjected to

$\sum_{i \in I} y_{i}=K$

$\sum_{j \in J} \sum_{t \in T}\left(\frac{X_{i j t s}}{\eta_{i j}}\right) \leq y_{i} \mathrm{SA}_{i s}, \quad \forall_{i \in I}, \forall_{s \in S}$

$\left(\left(\sum_{i} \sum_{s} X_{i j t s}+\operatorname{SDSM}_{j t}\right) \geq_{\alpha_{1}} \widetilde{D_{j t}}\right), \quad \forall_{j \in J, t \in T}$

$\sum_{t \in T} \operatorname{SDSM}_{j t} \leq P_{j}, \quad \forall j \in J$

$\sum_{t \in T}\left(\operatorname{SDSM}_{j t}\right) \geq \operatorname{SOBJ}_{j}, \quad \forall_{j \in J}$

$\operatorname{Dep}_{i t s}=B_{i s}\left(\frac{2}{N_{i s}}\right)\left(1-\frac{2}{N_{i s}}\right)^{t-1}, \quad \forall_{i \in I, s \in S, t \in T}$

$X_{i j t s}, \operatorname{SDSM}_{j t}, \operatorname{Dep}_{i t s} \geq 0, \quad \forall_{i \in I, s \in S, t \in T, j \in J}$

$y_{i} \in\{0,1\}, \quad \forall_{i \in I}$.

In objective function (1), the first term is related to the initial costs. The second term minimizes the total electricity generation cost over all periods. The third term is relevant to electricity saving cost. The last term considers the amount of equipment depreciation to be minimized. Objective functions (2) and (3) minimize total greenhouse gas emissions and water consumption, respectively. Constraint (4) limits the 
number of renewable energies that must be chosen. Equation (5) ensures that the amount of generating electricity does not exceed the capacity of corresponding resource. Constraint (6) assesses the number of demands which must be satisfied regarding the feasibility degree of $\alpha_{1}$ [19]. This constraint will be explained more completely in the next section. Equation (7) limits the amount of possible saving using the DSM program. Constraint (8) ensures that the amount of possible saving using the DSM program is larger than the least level. Constraint (9) calculates the depreciation of equipment using the declining balance method. In this method, depreciation in each year is computed by multiplying the depreciation rate, which is constant throughout the equipment's life, by the equipment's current basis. The basis is then reduced by the amount of the depreciation, and the procedure is repeated and (9) eventually exists. Finally, constraint (10) is related to the positive and binary variables.

\section{Defuzzification of the Model Using Jimenez's Technique}

In this section constraint (6) will be transformed to a crisp one using Jimenez's method. Consider a fuzzy constraint such as

$$
a_{i} x \geq_{\beta} \tilde{b_{i}}, \quad \forall_{i}=1, \ldots, l,
$$

where $x \in R^{n}$ is a $\beta$-feasible solution. In other words, the constraint (11) can be rewritten as follows:

$$
\min _{i=1, \ldots, l}\left\{\mu_{x}\left(a_{i} x, \tilde{b}_{i}\right)\right\}=\beta
$$

where $\mu_{x}\left(a_{i} x, \widetilde{b}_{i}\right)$ is membership function of the feasible area. To defuzzify the constraint, Jiménez et al. [19] proposed using the following equation for triangular fuzzy numbers (see (13)):

$$
\begin{gathered}
a_{i} x \geq \beta E_{2}^{b i}+(1-\beta) E_{1}^{b i}, \quad \forall_{i}=1, \ldots, l, \\
\text { If } \tilde{a}=\operatorname{TFN}(a 1, a 2, a 3, a 4), \\
E_{1}^{a}=\frac{(a 1+a 2)}{2}, \\
E_{2}^{a}=\frac{(a 3+a 4)}{2} .
\end{gathered}
$$

Thus, constraint (6) is defuzzified as follows:

$$
\begin{aligned}
\sum_{i} \sum_{s} X_{i j t s}+\operatorname{SDSM}_{j t} \geq & \frac{\alpha_{1}\left(D_{j t}^{m}+D_{j t}^{p}\right)}{2} \\
& +\frac{\left(1-\alpha_{1}\right)\left(D_{j t}^{m}+D_{j t}^{o}\right)}{2} .
\end{aligned}
$$

\section{Solution Methodology}

5.1. Fuzzy Goal Programming Model. In some problems when real life multiobjective problems occur, providing crisp definition of goal priorities is a very difficult task. In relative weight of importance among the goals uncertainty may be intrinsic or its relative importance may be vague from the decision maker viewpoint. The decision space and correlation between objectives may also have effects on the definition of important relations among the goals. The fuzzy goal programming approach is one of the best useful tools in confronting such problems. Applying fuzzy set theory in goal programming (GP) has the advantage that allows the decision maker to define imprecise aspiration levels [20,21].

To find the optimal solution of multiobjective problems, several methods have been introduced, such as weighted metric, weighted sum, $\varepsilon$-constraint, interactive approaches, and fuzzy goal programming (FGP). In this paper, we use FGP method to combine multiple objectives into a single objective.

Previously, applying a fuzzy goal programming approach to a multiobjective optimization problem was considered by $\mathrm{Hu}$ et al. [22]. Also, a fuzzy goal programming method with ambiguous goal hierarchy was studied by Aköz and Petrovic [20]. Iskander [23] employed a fuzzy weighted increasable approach. A basic method for solving fuzzy goal programming problems is max-min which is aptly used in the work of Yaghoobi and Tamiz [21]. A tolerance approach to the fuzzy goal programming problems was taken into account by Kim and Whang [24]. Also, a weighted max-min model for fuzzy goal programming was used in the work of Lin [25]. To see additional scholarly works conducted in the same field, the respected reader is referred to the studies of Saad [26], Martel and Aouni [27], Iskander [28], Chen and Tsai [29], Ramík [30], and Arora and Gupta [31].

To use FGP approach, three objective functions need to be defined as follows:

$$
\begin{aligned}
& \text { fuzzy goal 1: }(A X)_{i} \widetilde{\leq} b_{i} ; \\
& \text { fuzzy goal } 2:(A X)_{i} \simeq b_{i} ; \\
& \text { fuzzy goal } 3:(A X)_{i} \cong b_{i} .
\end{aligned}
$$

$t_{i}^{+}$and $t_{i}^{-}$are considered as the maximum acceptable errors for fuzzy goals 1 and 2, respectively. $t_{i}^{+}$is the quantity of a tolerance for the case of fuzzy goal 1 and $t_{i}^{-}$is for the case of fuzzy goal 2 and also the following relation exists:

$$
0<X_{n+1}<1 \text {. }
$$

In the following the way by which fuzzy goals are converted to LP constraints is elaborated.

For fuzzy goal 1,

$$
(A X)_{i}+t_{i}^{+} * X_{n+1} \leq b_{i} .
$$

Set $1-X_{n+1}=\beta_{i}^{+}$and then (16) is identical to $(A X)_{i}-$ $t_{i}^{+} * \beta_{i}^{+} \leq b_{i}$.

For fuzzy goal 2,

$$
(A X)_{i}-t_{i}^{-} * X_{n+1} \geq b_{i} .
$$

Set $1-X_{n+1}=\beta_{i}^{+}$and then (17) is identical to $(A X)_{i}+$ $t_{i}^{-} * \beta_{i}^{-} \geq b_{i}$ :

$$
1-X_{n+1}=\beta_{i}^{-} .
$$


TABLE 1: The value of parameters for renewable energy resources (the sign * shows that the data has been obtained hypothetically).

\begin{tabular}{lcccc}
\hline & Photovoltaic power & Wind power & Water power & Geothermal \\
\hline $\mathrm{GHG}_{i}\left(\mathrm{gCO}_{2}-e / \mathrm{kWh}\right)$ & 90 & 25 & 41 & 170 \\
$\mathrm{WC}_{i}(\mathrm{Kg} / \mathrm{kWh})$ & 10 & 1 & 36 & 100 \\
$\mathrm{Lu}_{i}(\mathrm{~mL} / \mathrm{kWh})$ & 0.046 & 0.072 & 0.0411 & $0.05^{*}$ \\
$\mathrm{SA}_{i s}(\mathrm{kWh})$ & $8000000 / \mathrm{s}$ & $327000 / \mathrm{s}$ & $555000 / \mathrm{s}$ & 0.039 \\
$C_{i j}(\$ / \mathrm{kWh})$ & 0.398 & 0.02 & 0.9 & 0.15 \\
$\eta_{i j}$ & 0.13 & 0.39 & $0000 / \mathrm{s}$ \\
\hline
\end{tabular}

TABLE 2: The value of parameters for end-uses.

\begin{tabular}{lcccc}
\hline & Domestic & Agriculture & General & Industrial \\
\hline $\mathrm{CDSM}_{j}$ & 0.183 & 0.238 & 0.917 & 0.055 \\
$P_{j}$ & 17433 & 18827 & 356 & 1270 \\
$\mathrm{SOBJ}_{j}$ & 5811 & 6276 & 119 & 423 \\
\hline
\end{tabular}

TABLE 3: The value of random parameters.

\begin{tabular}{lcc}
\hline Parameter & Range \\
\hline $\begin{array}{l}e_{i} \\
D_{j t}\end{array}=(0.8 * b, \text { uniform }[2000000-300000], 1.2 b)^{\mathrm{a}}$ & $r=0.15$ \\
$N_{i s}$ & $\sim$ uniform $(10-40)^{\mathrm{a}}$ & \\
$B_{i s}$ & $\sim$ uniform $(5000-10000)^{\mathrm{a}}$ & \\
\hline
\end{tabular}

${ }^{a}$ The value has been assumed by the authors.

For fuzzy goal 3,

$$
(A X)_{i}+t_{i}^{-} * \beta_{i}^{-}-t_{i}^{+} * \beta_{i}^{+}=b_{i}
$$

5.2. Formulating the Objective Function. The objective function of Narasimhan's model is to increase the grade of membership of the fuzzy goals. But the objective function of our model is to minimize tolerance permissible variables $\left(\beta_{i}^{-} / \beta_{i}^{+}\right)$whose ratio is tolerances $\left(t_{i}^{+}, t_{i}^{-}\right)$. If the values of $\left(\beta_{i}^{-} / \beta_{i}^{+}\right)$are minimized, the tolerances will get close to 0 for each fuzzy goal. Therefore, the degree of membership becomes larger. The objective function and its corresponding constraints are as follows:

$$
\begin{aligned}
& \min \sum_{i=1}^{k} w_{i} * \beta_{i}^{+} \\
& \quad(A X)_{i}-t_{i}^{+} * \beta_{i}^{+} \leq b_{i}, \\
& \min \sum_{i=1}^{k} w_{i} * \beta_{i}^{-} \\
& \quad(A X)_{i}+t_{i}^{-} * \beta_{i}^{-} \geq b_{i}, \\
& \min \sum_{i=1}^{k} w_{i} *\left(\beta_{i}^{-}+\beta_{i}^{+}\right) \\
& \quad(A X)_{i}+t_{i}^{-} * \beta_{i}^{-}-t_{i}^{+} * \beta_{i}^{+}=b_{i} .
\end{aligned}
$$

In the Narasimhan's model [32], all the fuzzy goals assumed have the identical importance or weight. Disparate weights in our model implicate that, between each goal, the importance is various. Our model to solve FGP problem with disparate weights is

$$
\begin{aligned}
\min & \sum_{i=1}^{k} w_{i} *\left(\beta_{i}^{-}+\beta_{i}^{+}\right) \\
& (A X)_{i}+t_{i}^{-} * \beta_{i}^{-}-t_{i}^{+} * \beta_{i}^{+}=b_{i}, \quad i=1,2, \ldots, k, \\
& t_{i}^{-}, \beta_{i}^{-}, t_{i}^{+}, \beta_{i}^{+} \geq 0, \quad x_{j} \geq 0, \quad j=1,2, \ldots, n, \\
& \sum_{i=1}^{k} w_{i}=1 .
\end{aligned}
$$

\section{Experimental Results}

To evaluate the proposed multiobjective model, which has been transformed to a single objective one using fuzzy goal programming method, 8 random instances have been solved. Some data in these problems are generated randomly using uniform distributions according to Table 3 and the rest are obtained from Kreith and Goswami [33], Herran and Nakata [34], and Evans et al. [35]. Also, there are a few parameters whose values have been determined hypothetically. Tables 1 and 2 show the value of parameters for renewable energy resources and for end-uses, respectively. Since LINGO 8.0 software is valid optimization software and solves the problems by Branch and Bound (B\&B) algorithm, we evaluate the problems with the solutions obtained by LINGO 8.0 for small-/medium- and large-sized problems.

It is worth mentioning that due to the popularity and availability of these resources and also because of the more conformity with a rural environment four popular energy resources and four general end-uses have been considered. Also, to keep generality of our model, the mean world energy data has been taken from the literature and used to validate the model and shows its applicability. Thus, no specific case has been considered in this paper. However, the respected readers are strongly recommended that they apply the proposed model in their specific cases and compare the obtained results to those obtained in our study by employing mean world data $[35,36]$.

Tables 1 and 2 present the parameter values of the model that are taken from data of global average and Kazemi and Rabbani [1]. 
TABLE 4: Sensitivity analysis.

\begin{tabular}{|c|c|c|c|c|c|c|c|}
\hline \multirow{2}{*}{ Number } & \multirow{2}{*}{$\begin{array}{l}\text { Problem size } \\
I * J * T * S\end{array}$} & \multicolumn{2}{|l|}{$\mathrm{B} \& \mathrm{~B}$} & \multicolumn{4}{|c|}{ Sensitivity analysis on parameter $\alpha$} \\
\hline & & Objective value $(\alpha=0.95)$ & Time (s) & 0.7 & 0.8 & 0.85 & 0.9 \\
\hline 1 & $2 * 2 * 3 * 2$ & 431180 & $<1$ & 340632.2 & 383750.2 & 396685.6 & 409621 \\
\hline 2 & $2 * 3 * 4 * 2$ & 684452 & $<1$ & 540717.1 & 609162.3 & 629695.8 & 650229.4 \\
\hline 3 & $3 * 3 * 4 * 3$ & 706904 & $<1$ & 163454.2 & 184144.6 & 190351.7 & 196558.8 \\
\hline 4 & $4 * 4 * 10 * 7$ & 874562 & $<1$ & 690904 & 778360.2 & 804597 & 830833.9 \\
\hline 5 & $5 * 4 * 10 * 8$ & 954653 & $<1$ & 754175.9 & 849641.2 & 878280.8 & 906920.4 \\
\hline 6 & $5 * 4 * 20 * 12$ & 3954563 & 5 & 3124105 & 3519561 & 3638198 & 3756835 \\
\hline 7 & $5 * 4 * 30 * 20$ & 4364795 & 10 & 3448188 & 3884668 & 4015611 & 4146555 \\
\hline 8 & $5 * 4 * 40 * 20$ & 5225678 & 34 & 4128286 & 4650853 & 4807624 & 4964394 \\
\hline
\end{tabular}

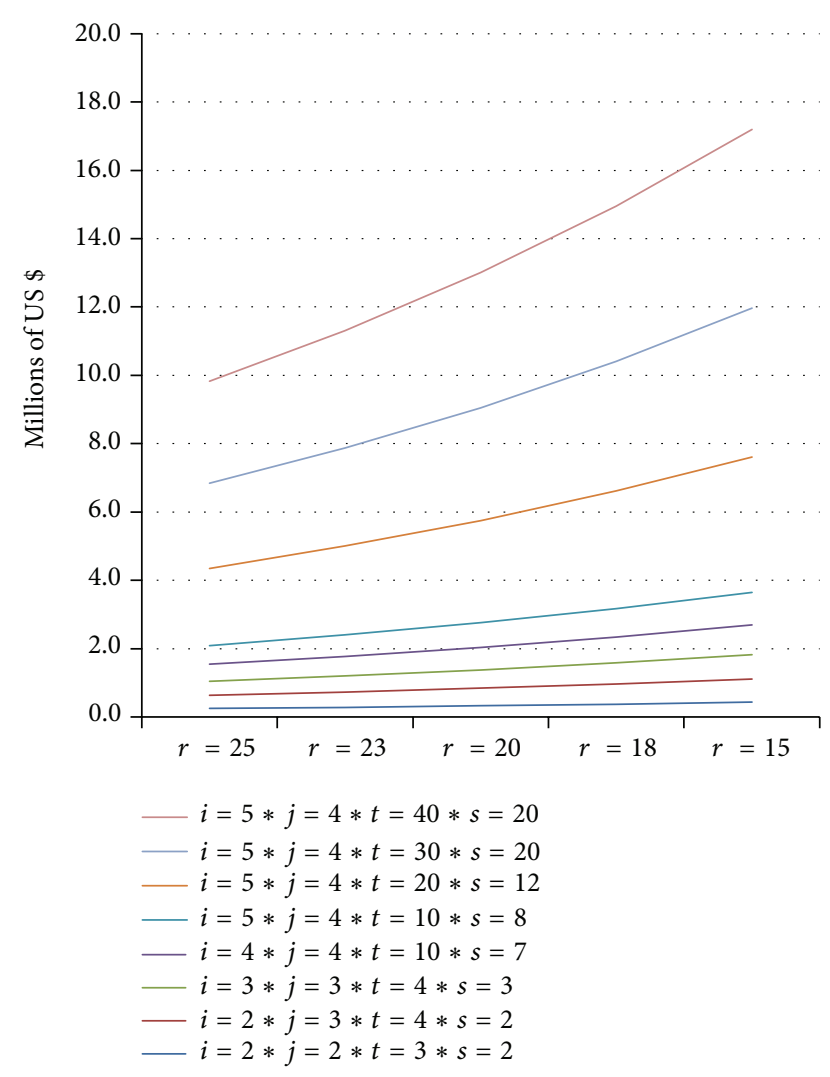

FIGURE 1: Sensitivity analysis on capital rate of return.

Table 4 shows the objective function values and the run times obtained by LINGO on an Intel_Celeron_Mobile $2.5 \mathrm{GHz}$ (Core 2 Duo) personal computer with $3 \mathrm{~GB}$ RAM. According to the results we conclude that the proposed multiobjective model is solved by $\mathrm{B} \& \mathrm{~B}$ algorithm in a reasonable time even for large-sized problems.

As shown in Figure 1, sensitivity analysis on capital rate of return has been conducted. It is mostly due to the fact that the parameter has an inconsistent nature and is subject to change depending on different periods of time. As was expected, the higher the parameter IRR is, the more costly the planning decisions will be.

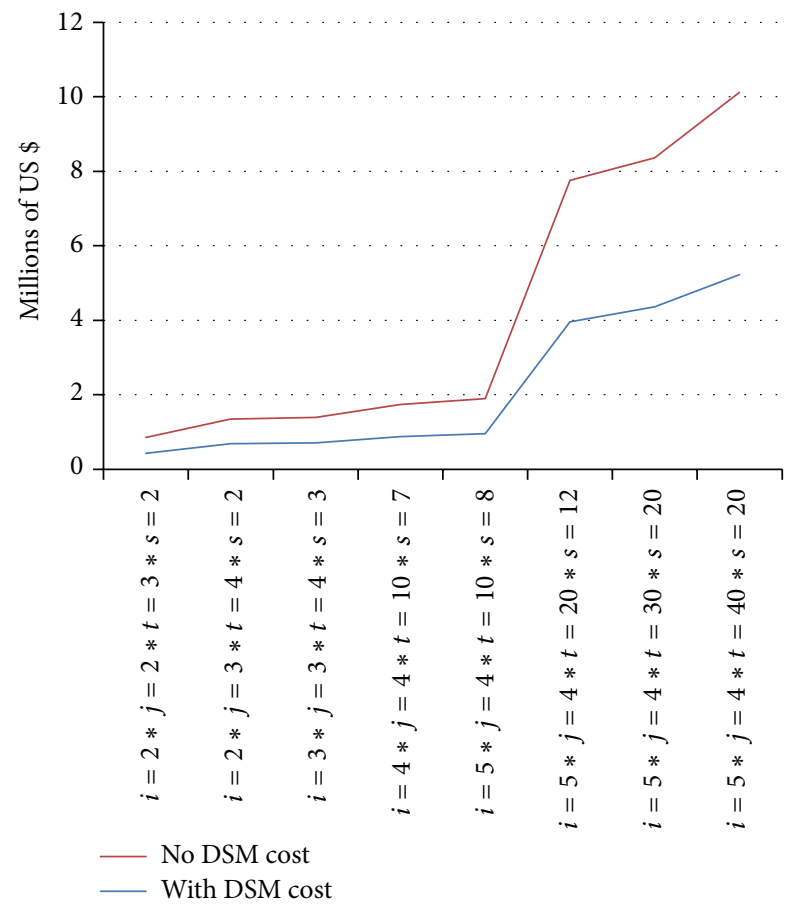

Figure 2: Contribution of considering DSM programs to the total establishment costs of a network.

Figure 2 shows the positive contribution of considering DSM programs to the total establishment costs of a network. To obtain the line charts shown in Figure 2, the model was firstly solved for different test problems without considering DSM programs and the outputs are shown by the red line chart (the above one). Afterward the model was solved for the second time when DSM programs were taken into account; the corresponding results are shown using the blue line chart (the below one). It can be concluded that employing DSM programs not only has gains in terms of environmental measures but also, as shown in Figure 2, brings about great money savings across the network and the savings become more visible when the size of the problems increases, that is, for real-sized problems.

Figure 3 shows that increasing the value $\alpha_{-}$cut will incur additional costs. It also renders the impact parameter $I$ with 
TABLE 5: Experimental results.

\begin{tabular}{|c|c|c|c|c|c|c|}
\hline \multirow{2}{*}{ Number } & \multicolumn{2}{|l|}{ Problem size } & \multicolumn{4}{|c|}{ Sensitivity analysis on amount of percent using renewable energy } \\
\hline & $I * J * T * S$ & Photovoltaic power & Geothermal & Wind power & Water power & DSM \\
\hline 1 & $2 * 2 * 3 * 2$ & $16 \%$ & $17 \%$ & $24 \%$ & $22 \%$ & $21 \%$ \\
\hline 2 & $2 * 3 * 4 * 2$ & $15 \%$ & $16 \%$ & $25 \%$ & $21 \%$ & $21 \%$ \\
\hline 3 & $3 * 3 * 4 * 3$ & $13 \%$ & $17 \%$ & $27 \%$ & $23 \%$ & $20 \%$ \\
\hline 4 & $4 * 4 * 10 * 7$ & $15 \%$ & $16 \%$ & $28 \%$ & $22 \%$ & $19 \%$ \\
\hline 5 & $5 * 4 * 10 * 8$ & $16 \%$ & $17 \%$ & $24 \%$ & $23 \%$ & $20 \%$ \\
\hline 6 & $5 * 4 * 20 * 12$ & $14 \%$ & $15 \%$ & $26 \%$ & $23 \%$ & $22 \%$ \\
\hline 7 & $5 * 4 * 30 * 20$ & $15 \%$ & $16 \%$ & $28 \%$ & $21 \%$ & $20 \%$ \\
\hline \multirow[t]{2}{*}{8} & $5 * 4 * 40 * 20$ & $15 \%$ & $17 \%$ & $27 \%$ & $22 \%$ & $19 \%$ \\
\hline & Average & $15 \%$ & $16 \%$ & $26 \%$ & $22 \%$ & $20 \%$ \\
\hline
\end{tabular}

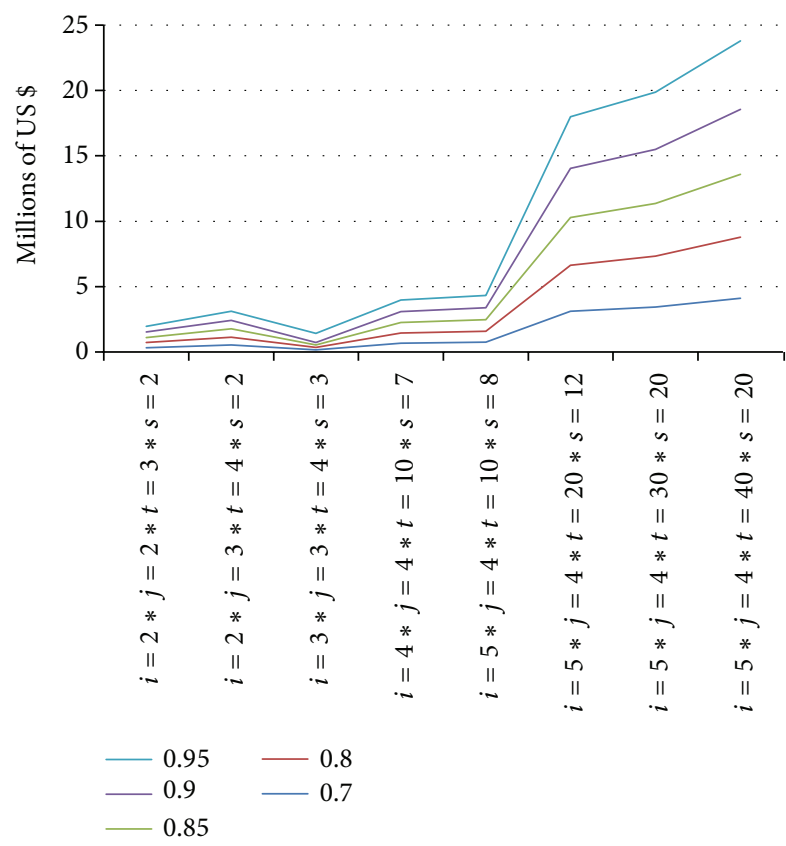

FIGURE 3: Sensitivity analysis on $\alpha_{-}$cut against costs.

respect to $J, S$, and $T$ in Table 5 . Increasing 1 unit in the amount of parameter $I$ the total cost will be added to the 100000 .

In Table 5, the outcomes of the optimization model are illustrated. As the average values imply, based on all the criteria considered in the model, wind power is superior to all other resources followed by hydropower and DSM policies. On the other hand, under the given conditions, use of photovoltaic and geothermal technologies is not recommended.

\section{Conclusions}

In this paper, four renewable energy options and four enduses were considered. To obtain the optimal amount of energy transferred from each option to each end-use, a mixed integer fuzzy multiobjective formulation was proposed.
The model seeks out the optimal solution that simultaneously minimizes three objective functions, namely, total cost, water consumption, and greenhouse gas emissions. Because of the inherent uncertainty existing in the nature of the demand parameter, fuzzy numbers were used for enhanced modeling. In addition, as these projects are usually launched to work in the long run, the time value of money was also considered in the proposed model. To change the multiobjective fuzzy programming model to a single-objective one the wellknown fuzzy goal programming method was applied.

The findings of the paper indicate that considering DSM programs as an option can greatly contribute to saving of thousands of US dollars. Moreover a general ranking based on the considered criteria has been produced. According to the ranking, wind power is superior to all other resources followed by hydropower and DSM policies while using photovoltaic and geothermal is not a favorite choice and is not recommended.

\section{Conflict of Interests}

The authors declare that they have no conflict of interests.

\section{Acknowledgments}

The authors sincerely thank the reviewers for their constructive comments which resulted in great improvement in the quality of the paper.

\section{References}

[1] S. M. Kazemi and M. Rabbani, "An integrated decentralized energy planning model considering demand-side management and environmental measures," Journal of Energy, vol. 2013, Article ID 602393, 6 pages, 2013.

[2] T. Nakata, K. Kubo, and A. Lamont, "Design for renewable energy systems with application to rural areas in Japan," Energy Policy, vol. 33, no. 2, pp. 209-219, 2005.

[3] M.-L. Barry, H. Steyn, and A. Brent, "Selection of renewable energy technologies for Africa: eight case studies in Rwanda, Tanzania and Malawi," Renewable Energy, vol. 36, no. 11, pp. 2845-2852, 2011. 
[4] M. M. Ardehali, "Rural energy development in Iran: nonrenewable and renewable resources," Renewable Energy, vol. 31, no. 5, pp. 655-662, 2006.

[5] S. J. Benson and S. Asgarpoor, "A fuzzy expert system for evaluation of demand-side management alternatives," Electric Machines and Power Systems, vol. 28, no. 8, pp. 749-760, 2000.

[6] J. J. Hain, G. W. Ault, S. J. Galloway, A. Cruden, and J. R. McDonald, "Additional renewable energy growth through small-scale community orientated energy policies," Energy Policy, vol. 33, no. 9, pp. 1199-1212, 2005.

[7] A. Bergmann, N. Hanley, and R. Wright, "Valuing the attributes of renewable energy investments," Energy Policy, vol. 34, no. 9, pp. 1004-1014, 2006.

[8] D. R. Thiam, "An energy pricing scheme for the diffusion of decentralized renewable technology investment in developing countries," Energy Policy, vol. 39, no. 7, pp. 4284-4297, 2011.

[9] A. Bergmann, S. Colombo, and N. Hanley, "Rural versus urban preferences for renewable energy developments," Ecological Economics, vol. 65, no. 3, pp. 616-625, 2008.

[10] B. Mainali and S. Silveira, "Renewable energy markets in rural electrification: country case Nepal," Energy for Sustainable Development, vol. 16, no. 2, pp. 168-178, 2012.

[11] W. Wolde-Ghiorgis, "Renewable energy for rural development in Ethiopia: the case for new energy policies and institutional reform," Energy Policy, vol. 30, no. 11-12, pp. 1095-1105, 2002.

[12] B. Zhu, W. Zhang, J. Du, W. Zhou, T. Qiu, and Q. Li, “Adoption of renewable energy technologies (RETs): a survey on rural construction in China," Technology in Society, vol. 33, no. 3-4, pp. 223-230, 2011.

[13] R. B. Hiremath, B. Kumar, P. Balachandra, N. H. Ravindranath, and B. N. Raghunandan, "Decentralised renewable energy: scope, relevance and applications in the Indian context," Energy for Sustainable Development, vol. 13, no. 1, pp. 4-10, 2009.

[14] W. Liu, C. Wang, and A. P. J. Mol, "Rural public acceptance of renewable energy deployment: the case of Shandong in China," Applied Energy, vol. 102, pp. 1187-1196, 2013.

[15] H. Liming, "Financing rural renewable energy: a comparison between China and India," Renewable and Sustainable Energy Reviews, vol. 13, no. 5, pp. 1096-1103, 2009.

[16] H. Winkler, A. Hughes, and M. Haw, "Technology learning for renewable energy: implications for South Africa's long-term mitigation scenarios," Energy Policy, vol. 37, no. 11, pp. 49874996, 2009.

[17] P. Purohit, A. Kumar, S. Rana, and T. C. Kandpal, "Using renewable energy technologies for domestic cooking in India: a methodology for potential estimation," Renewable Energy, vol. 26, no. 2, pp. 235-246, 2002.

[18] L. Zhang, Z. Yang, B. Chen, and G. Chen, "Rural energy in China: pattern and policy," Renewable Energy, vol. 34, no. 12, pp. 2813-2823, 2009.

[19] M. Jiménez, M. Arenas, A. Bilbao, and M. V. Rodríguez, "Linear programming with fuzzy parameters: an interactive method resolution," European Journal of Operational Research, vol. 177, no. 3, pp. 1599-1609, 2007.

[20] O. Aköz and D. Petrovic, "A fuzzy goal programming method with imprecise goal hierarchy," European Journal of Operational Research, vol. 181, no. 3, pp. 1427-1433, 2007.

[21] M. A. Yaghoobi and M. Tamiz, "A method for solving fuzzy goal programming problems based on MINMAX approach," European Journal of Operational Research, vol. 177, no. 3, pp. 15801590, 2007.
[22] C.-F. Hu, C.-J. Teng, and S.-Y. Li, "A fuzzy goal programming approach to multi-objective optimization problem with priorities," European Journal of Operational Research, vol. 176, no. 3, pp. 1319-1333, 2007.

[23] M. G. Iskander, "A fuzzy weighted additive approach for stochastic fuzzy goal programming," Applied Mathematics and Computation, vol. 154, no. 2, pp. 543-553, 2004.

[24] J. S. Kim and K.-S. Whang, "A tolerance approach to the fuzzy goal programming problems with unbalanced triangular membership function," European Journal of Operational Research, vol. 107, no. 3, pp. 614-624, 1998.

[25] C.-C. Lin, "A weighted max-min model for fuzzy goal programming," Fuzzy Sets and Systems, vol. 142, no. 3, pp. 407-420, 2004.

[26] O. M. Saad, "An iterative goal programming approach for solving fuzzy multiobjective integer linear programming problems," Applied Mathematics and Computation, vol. 170, no. 1, pp. 216225, 2005.

[27] J.-M. Martel and B. Aouni, "Diverse imprecise goal programming model formulations," Journal of Global Optimization, vol. 12, no. 2, pp. 127-138, 1998.

[28] M. G. Iskander, "Exponential membership function in stochastic fuzzy goal programming," Applied Mathematics and Computation, vol. 173, no. 2, pp. 782-791, 2006.

[29] L.-H. Chen and F.-C. Tsai, "Fuzzy goal programming with different importance and priorities," European Journal of Operational Research, vol. 133, no. 3, pp. 548-556, 2001.

[30] J. Ramík, "Fuzzy goals and fuzzy alternatives in goal programming problems," Fuzzy Sets and Systems, vol. 111, no. 1, pp. 81-86, 2000.

[31] S. R. Arora and R. Gupta, "Interactive fuzzy goal programming approach for bilevel programming problem," European Journal of Operational Research, vol. 194, no. 2, pp. 368-376, 2009.

[32] R. Narasimhan, "Goal programming in a fuzzy environment," Decision Sciences, vol. 11, pp. 325-326, 1980.

[33] F. Kreith and D. Y. Goswami, Energy Management and Conservation Handbook, CRC, 2008.

[34] D. Silva Herran and T. Nakata, "Renewable technologies for rural electrification in Colombia: a multiple objective approach," International Journal of Energy Sector Management, vol. 2, no. 1, pp. 139-154, 2008.

[35] A. Evans, V. Strezov, and T. J. Evans, "Assessment of sustainability indicators for renewable energy technologies," Renewable and Sustainable Energy Reviews, vol. 13, no. 5, pp. 1082-1088, 2009.

[36] A. B. Kanase-Patil, R. P. Saini, and M. P. Sharma, "Integrated renewable energy systems for off grid rural electrification of remote area," Renewable Energy, vol. 35, no. 6, pp. 1342-1349, 2010. 


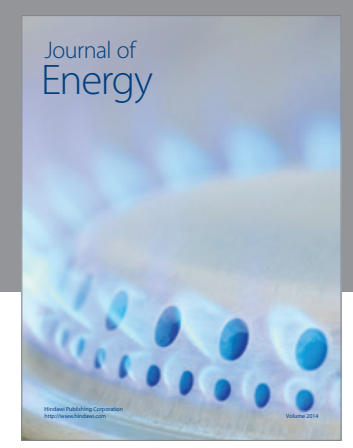

Journal of

Industrial Engineering
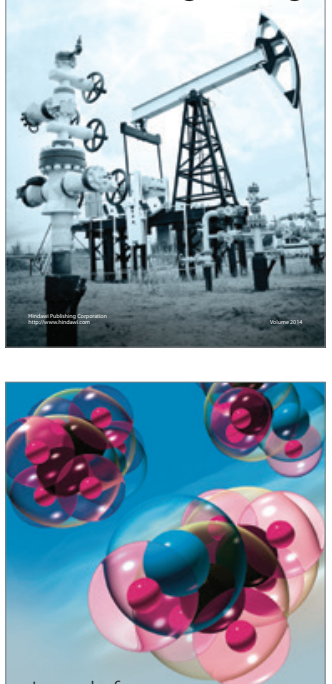

Fuels
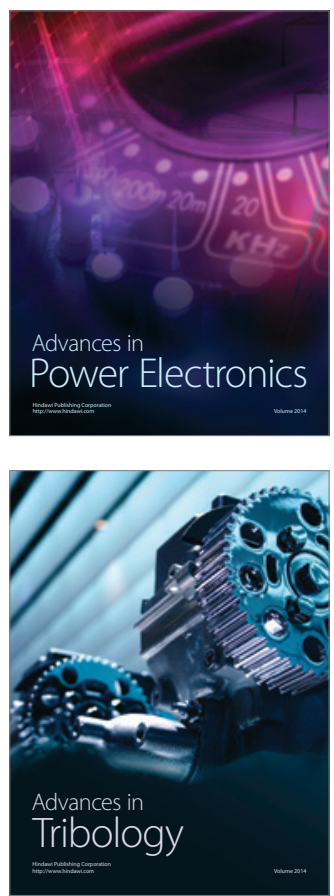

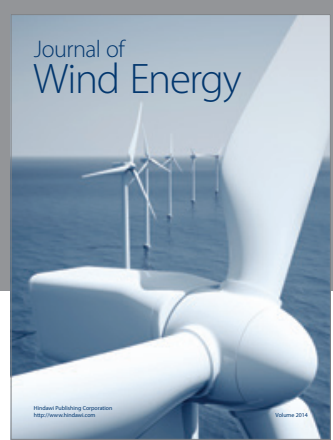

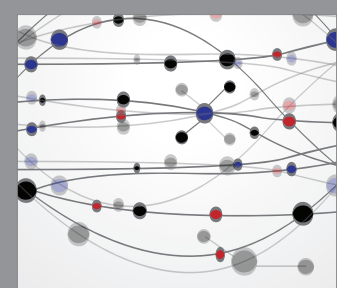

The Scientific World Journal

Submit your manuscripts at http://www.hindawi.com

Journal of

Structures
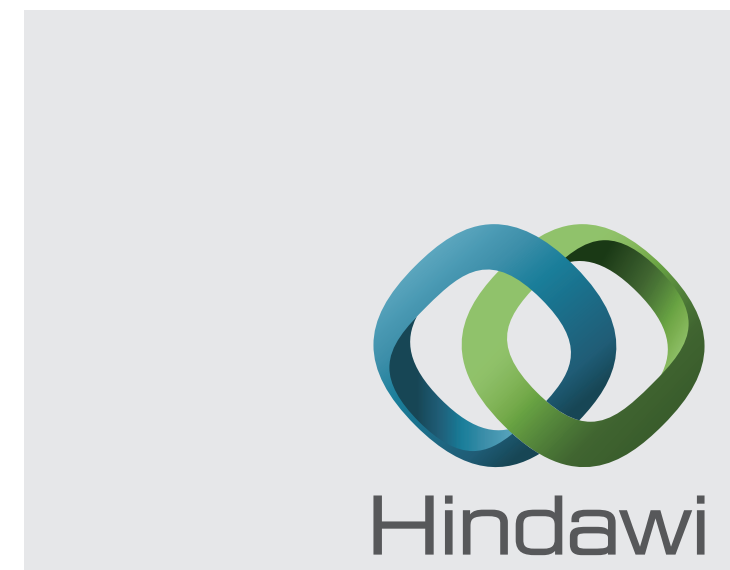

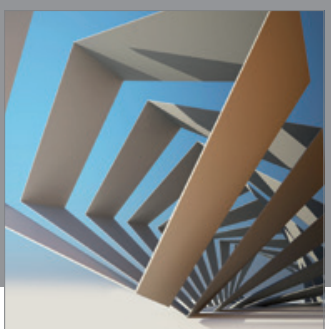

Rotating

Machinery
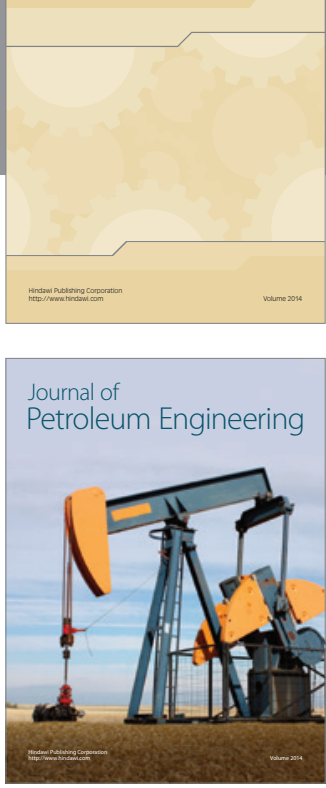

Journal of

Solar Energy
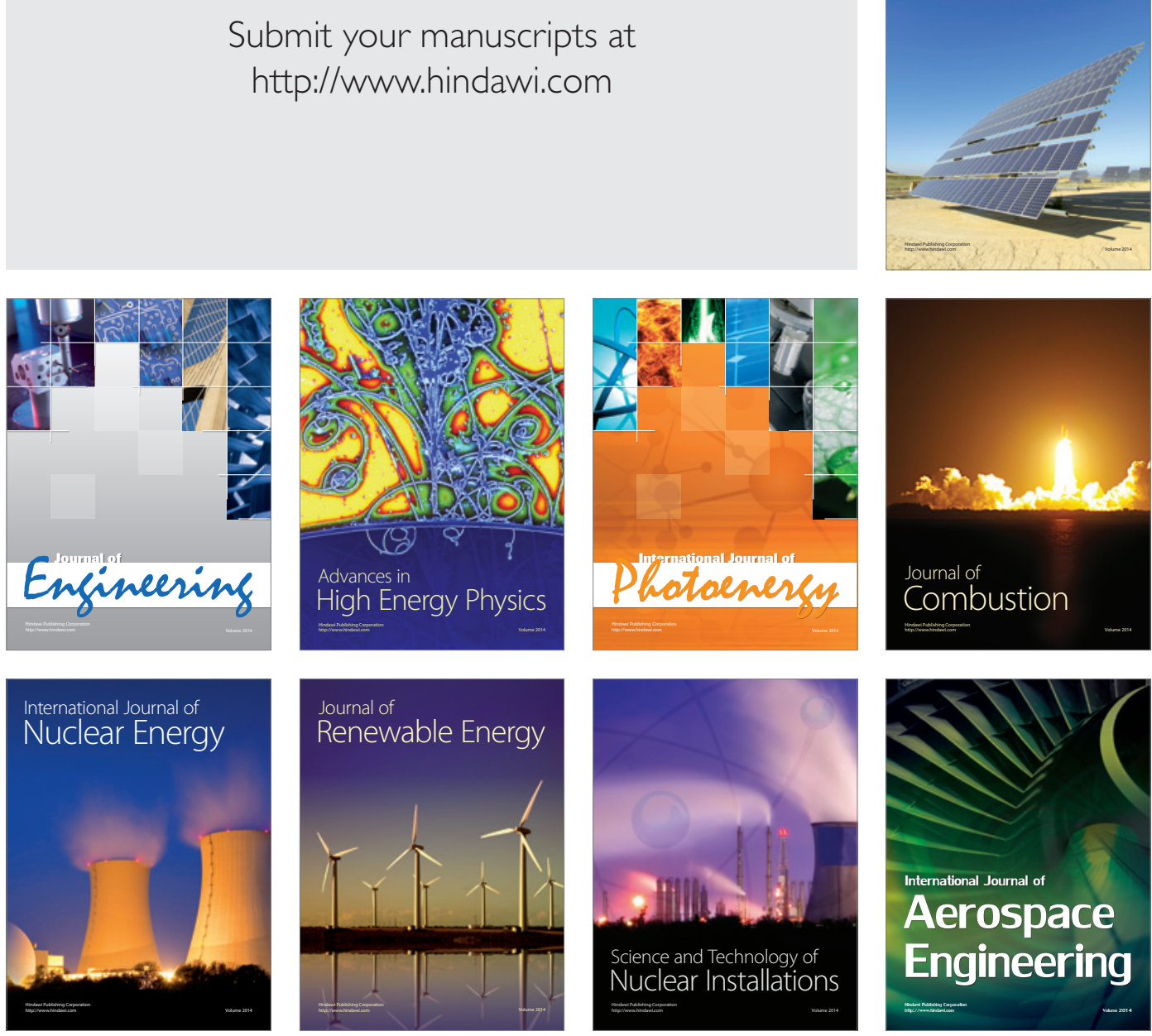